\title{
The need of dermatologists, psychiatrists and psychologists joint care in psychodermatology*
}

\author{
Roberto Doglia Azambuja ${ }^{1}$
}

DOI: http://dx.doi.org/10.1590/abd1806-4841.20175493

\begin{abstract}
The mind-skin connection has been studied since the nineteenth century. The last 40 years have set the development of new research areas which allowed the clarifying of how these two dimensions interact. The diseases that involve skin and mind constitute the field of psychodermatology and require that specialists in dermatology, psychiatry and psychology together and integrated take part in it, since skin, nervous system and mind are simultaneously affected. This paper aims to expose how psychodermatoses are currently conceptualized and the need of integration of these three specialties for conveniently treating the patients.
\end{abstract}

Keywords: Integrative medicine; Psychopharmacology; Psychotherapy; Stress, Psychological

\section{INTRODUCTION}

From the research of Robert Ader (1932-2011) in the 1970s, which originated psychoneuroimmunology, Western medicine began to accept that mind and body are related and that this relation causes them to be interrelated all the time through chemical substances and cellular receptors. ${ }^{1}$

From these observations - to which new data are added every day - science gave light to what hitherto was a true dogma in allopathic medicine: that the cause of diseases should be sought exclusively in physical matter and they could be altered only through material means. Energy, mind, and emotions were not considered in the genesis or course of disease, and even less in healing and health.

A great deal of research and evidence that mind and body form an indivisible unity has given way to a growing interest of doctors for new knowledge, thus broadening their vision and the resources they use in what is being called Mind-body Medicine, Integrative Medicine or Biopsychosocial Medicine. ${ }^{2}$

An eloquent example of this new consciousness are the socalled "humanization of medicine programs", a designation that indicates the recognition that the current model excluded the sick person and focused exclusively on signs and symptoms, transforming the disease into a separate entity of the individual affected by it.

Finally, medicine is taking into consideration the reality that most diseases are multifactorial, being formed by previous situations whose effects are accumulating in the body. The whole life history of the person gives indications of circumstances in which each one is exerting a certain role to culminate in some clinical picture. Thus, gestational and birth conditions, pathological anteced- ents, parents' lifestyle, family environment, physical environment in childhood, physical and emotional traumatic experiences in early childhood, emotions felt by the way one was treated, traumatic experiences in adolescence, the moment in life of disease onset, the worsening conditions in its evolution, the tendency of positive or negative thoughts of the patient, family, social, sexual, financial conditions, belief system, tendency to optimism or pessimism are own and unique factors for each person, making the disease a particular and specific state of the individual who presents it. In every process of illness, there are biological, psychological, emotional, social and spiritual contributions.

Dermatology participates in this scientific development, and much more than the other fields of medicine, because everything that affects the skin is visible to people as well as to the patient himself. From this follows, in addition to the unpleasant physical sensations that take the person off balance, creating discomfort, irritation and impatience, damage to the physical appearance, which compromises the individual's self-image and attains one's self-esteem.

The concept that focuses on the skin as a reflection of the mind and emotions and at the same time influences these two spheres has always existed, because emotional states such as fear, shame, anger, and terror, are manifested by changes in color, texture, moisture and skin attachments as well as mental states, such as depression, anxiety and distortion of body image, are created by skin disorders. 
However, the impossibility of material evidence of the mechanism of this relation made it difficult for dermatologists to accept its reality. From 1984, with the publication of the book Psychosomatic Dermatology: Stress and Skin Diseases, by Professor Emiliano Panconesi, from Florence, Italy, in which the results of the researches in Psychoneuroimmunology were already used, several experimenters, authors and clinicians began to spread the mindskin interaction and the need for care beyond classical dermatology, in what was already called Psychosomatic dermatology, and today, more generally, it is called Psychodermatology.

This is a dermatological subspecialty and is also a concept applicable to all Dermatology.

It can be considered a subspecialty when it is included the group of dermatoses classified as psychodermatoses.

In a broader sense, the psychodermatological view encompasses any and all skin diseases, since they can all have reflexes in the mood and mental and emotional balance of people.

Thus, dealing with the patient and the treatment to be employed will require a more comprehensive performance of the dermatologist because he/she will have to be prepared to recognize mental and emotional states that accompany dermatoses and to give psychological support to the patient, starting with a highly effective physician-patient relationship, stress management resources and even psychopharmacological and psychological therapies. In addition to his/her skills, he/she will need the integration with professionals in Psychology and Psychiatry to attend specific cases of these specialties.

This cooperation between Dermatology and Psychology becomes essential in cases in which there is a predominant psychological event as the starting point of the dermatosis or in cases in which the dermatosis has damaging and unbalancing effect on the psyche. In these situations, it is necessary to perform a psychodiagnosis and to attend the patient with specific and effective techniques, specific to the professional of Psychology. In other situations, such as skin problems secondary to mental disorders or dermatoses that accompany or arise from anxiety, depression, hypochondria, delusions and hallucinations, the dermatologist must rely on the psychiatrist for appropriate psychopharmacological management.

Therefore, Psychodermatology is a field of integrated action of three specialties without which it will not be possible to give the appropriate care to the patient. It should be added that the participation of Psychology and Psychiatry will not always result in the elimination of the disease. In many cases the objective is not a complete cure but the attention to the mental and emotional states that are part of the clinical picture in order to at least give the patient resources to deal with the problem in a balanced and autonomous manner. ${ }^{3-5}$

\section{TOUCHING THE SKIN}

Psychodermatology begins by considering the profound effects on the psyche and on the physical and physiological development of the individual caused simply by touching the skin. This is a magical mechanism performed by the skin, which should be in the consciousness of every dermatologist. The skin is the wrapper and the boundary between the individual and the surround- ing environment, with the multiple and extraordinary functions of barrier, emunctory, thermoregulatory, photoprotective, metabolic, endocrine, storage, blood pressure and blood flow regulator and advanced immunovigilance. Beyond that, the skin receives and interprets the information coming from the central nervous system via chemical messengers and produces all mediator substances originated from the brain to give them retrogrades information, playing a human feature that may be the difference between life and death. This ability to produce the same substances as the brain makes the skin an external brain. ${ }^{6}$

The touch on the skin activates the sensory corpuscles of which it is endowed and that enable the sense of tact. Through it, the skin is continually stimulated by the external environment and carries information to the brain all the time. This allows the brain to make adjustments according to the stimuli captured by the skin. There is a permanent feedback loop between the skin and the brain, which occurs even during sleep. This connection influences not only the physical development of the individual but also the psychological. The British anatomist Ashley Montagu (1905-1999) paid special attention in his research to the sense of touch. In his book Touching - The Human Significance of the Skin, he focused on skin's role in birth, neurological development, breastfeeding, affective learning, immune function, growth, sex, culture, and maturation. ${ }^{7}$ This book should be studied by every candidate for dermatology before beginning the contact with dermatoses in order to understand the profound physical and psychological influence of the skin and its meaning in people's lives. According to Montagu, "tactile sensations become tactile perceptions according to the meanings from which they have been invested by experience. Inadequate tactile experiences will result in a lack of such associations and in a consequent inability to create fundamental relationships with others. When affection and involvement are transmitted by touch, it is with these meanings, besides the provision of security through satisfactions, that touch becomes associated. This is the human meaning of touching".

Touch deprivation and somesthetic stress (pain and touch trauma) lead to rapid rise in plasma cortisol levels, which indicates to the body an environmental change or stress. Chronic alteration in the balance of plasma cortisol and other hormones and chemical mediators leads to abnormal development of brain tissue and destruction of this previously normal tissue. On the other hand, tender and loving touch is associated with low levels of plasma cortisol, resulting in positive changes in brain tissue. ${ }^{8}$

Patterson and Hidore report that, in 1945, the physician and psychoanalyst René Spitz (1897-1974) compared children living in an orphanage and children admitted to the infirmary of a penal establishment where their mothers were imprisoned. The physical conditions of the orphanage and the state of development of the children were better than those of the penal institution, but sickness and death rates at the orphanage were greater than those in the prison, and by the end of one year the children in the orphanage were worse than the ones living in the prison. After two years, 37 children of the orphanage had died; in prison, all were alive after five years. The difference between the two situations was that in prison mothers took care of their children and in the orphanage they 
were cared by professional nurses. ${ }^{9}$ Spitz noted that the babies of the orphanage were fed and clothed, but received neither the affection of the mothers nor were carried in the lap, were not physically stimulated nor cuddled. At the end of three months, they had a state he called the hospitalism syndrome. These children had difficulty in physical development, lost their appetite, didn't gain weight and adopted a position of defense and isolation and this led the majority to death. Spitz's work drew attention to the consequences of the isolation of children in institutions, and this influenced a change in attitude, which involved frequent skin stimulation, with a drastic drop in deaths at these orphanages.

Later work, based specifically on touching, confirmed the fundamental effect of cutaneous stimulation on the development of infants. Dr. Tiffany Field, of the University of Miami, released in 1986 an observation performed in the infirmary of premature infants. Accompanying two groups of preterm infants - one that was normally touched for diapering, bathing and feeding, and other that, in addition to the usual care, received caressing for 15 minutes three times a day - she noted that the group that were stimulated presented an increased weight $47.8 \%$ per day and was discharged six days earlier compared with the other group. ${ }^{10}$

\section{THE DERMATOLOGICAL CONSULTATION}

With all this complexity of the skin, the dermatological consultation in many cases needs to go beyond anamnesis, physical examination, diagnosis and treatment. In the daily clinic, all dermatologists face patients who present complaints that are not related to the present skin problem, references to daily events, perceptions, beliefs, interpretations of facts, emotional impacts, experiences, afflictions, frustrations, sadness, depression, heartache, anxiety, and other reports of a psychological and emotional nature. How many times does the dermatologist have to answer the question: "Is it because of stress?" How many times a day the clinician hears the patient's spontaneous statement: "I am very stressed/ anxious/ I cannot wait/ I want everything done yesterday/ I want everything perfect?". It is necessary to know that these statements, although they cannot be seen, palpated, biopsied and dosed, are almost always related to the clinical picture and must be taken into consideration for patient satisfaction and for the treatment to go beyond surface changes, which are the effect. It is necessary to reach the origins, which, although it may seem strange to the biomedical model, can be placed in energy levels previous to those of the physical body.

Moreover, it is necessary to pay attention to the emotional state of the patient caused by the dermatosis. How can a young woman with beautiful hair feel when alopecia areas appear, which do not respond to treatments and progress in an unavoidable way? What does the dermatologist have to say to her? Does the phrase "You have to accept this", issued as advice by many experts, give some perspective to the patient? So also in cases of pustular acne in adolescents, linear scleroderma on the face, vitiligo mainly in the hands, melasma, early baldness, psoriasis, and practically all dermatoses.

Because they are visible to other people, who frequently inquire about the change, almost all dermatoses affect, to a greater or lesser degree, the emotional state of the patients and this has to in- terest the dermatologist. Whether as a causative, triggering, aggravating or consequent factor, emotional states of dislike, disgust, fear, shame and anger are part of the clinical picture and need attention as much as the cutaneous picture. The incidence of psychological or psychiatric disorders in dermatological patients varies according to the type of disease, the location in visible areas and the social level of the patients. ${ }^{11-15}$ As dermatologists pay attention to the psychological and social commitment, a biopsychosocial view of dermatoses is required, which implies considering what is going on in the patient's mind and environment along with dermatological factors to manage the disease. The breakdown of physical or psychic balance and any overload in both spheres generates stress, which has harmful consequences on all organs, including the skin.

\section{STRESS}

Being stressed is one of the most common complaints heard in a doctor's office. And we must give credit to this, because the current pace of life is incompatible with a healthy body. The human body does not have the structure to be bombarded incessantly every day by aggressions, such as strenuous work rhythm, highly oxidizing diet, introduction of lethal agents such as alcohol, tobacco and drugs, daily use of drugs with unpredictable adverse events, depletion of energy in traffic, noise pollution, as well as unnatural, short, shallow and choppy sleep. To all this can be added real psychological and emotional situations, such as pressure on production at work, financial difficulties, unemployment risk, affective problems in marriage and in family, loss of significant people, insecurity in cities, excessive information by newspapers, magazines, radio, television and internet, real or imagined situations, with fears about things that can happen, concern for future events, guilt for the past, frustrations for failure to achieve goals, low self-esteem, negative self-image, lack of confidence, and, also, corrosive emotions fed as if they were points of honor, such as anger, resentment, hurt, hatred, desire for revenge, ingratitude, which affect balance and behavior and generate permanent stress.

All this gives rise to a completely unbalanced condition for the human organism, which must be adapting itself all the time and, still unable to recover from one blow, already receives another. This imbalance condition generates free radical production higher than the enzymes can neutralize and, as a consequence, tissue inflammation, aging and degeneration. "The hormones associated with the chronic stress load protect the body in the short term and promote adaptation (allostasis), but in the long run, this burden causes changes in the brain and body that can lead to disease (allostatic load). The result is the breakdown of homeostasis and the allostatic load, which are damaging changes that can accumulate in response to stress". ${ }^{16}$

The skin is particularly affected by stress and it is important to always keep in mind the role it may be playing in the generation, aggravation or maintenance of dermatoses.

Stress can be defined as the set of responses and physiological adaptations that occurs in the body whenever a perceived threat, real or imagined, affects physical, mental and emotional balance. It was initially studied and clarified by the Viennese researcher Hans Selye, at McGill University in Canada, and first published in 1936. ${ }^{17}$ 


\section{MIND AND BRAIN IN RELATION TO THE IMMUNE SYSTEM}

People refer to the mind as if there is a common sense about their existence and nature. However, there continues to be a discussion among psychiatrists, neurologists, and neuroscientists about what, in essence, is the mind. For many, the mind is the product of the brain and, once produced by it, acts retrograde and dominates it. As Rick Hanson, a neuropsychologist, and Richard Mendius, a neurologist, put it: "Nobody knows exactly how the brain generates the mind or how the mind uses the brain to form the mind". Although this phrase is barely intelligible, they further assert, "You are able to use the mind to improve the brain". ${ }^{18}$ That is, they assert that each one has the ability to use something immaterial and unknown to modify a concrete structure such as the brain. This shows the confusion of the understanding of what is the mind. Leonard Mlodinov, professor of physics at the California Institute of Technology, has no doubt: "... the origin of the mind lies in the physical substance of the brain". ${ }^{19}$ Some are more radical, admitting no other hypothesis, such as the psychiatrist Henrique Schützer Del Nero, who states, refuting the possibility of someone getting out of a psychological malaise by the force of thought: "... thought is a product of the brain and not the other way around. If there are bad thoughts, it will not be the intervention of the thought that will rescue the good functioning of the brain", going in the opposite direction to what Psychoneuroimmunology has scientifically demonstrated since $1970 .{ }^{20}$

On the other hand, there are scientists who have come to the conclusion, through their experiences, that the mind exists independently of the brain and, as the research in Psychoneuroimmunology has shown, effectively commands the central organ. Among them is Wilder Graves Penfield (1891-1976), a naturalized Canadian citizen, one of the greatest neurosurgeons of the 20th century, who conducted several researches on the location of the epilepsy focus. He found that substantial areas of the cerebral cortex can be removed without any loss of consciousness by the individual, a fact that would suggest that consciousness is not specifically localized. Penfield noted that the history of the development of the mind during life is opposite to that of the brain. In the curve of human physical performance, there is improvement until a certain age, and from there, functions begin to decline and lose effectiveness until senility. On the contrary, the mind does not reveal inevitable decline and reaches the maximum potential of understanding and judgment in old age. Penfield states: "In the end, I conclude that there is no good evidence, despite new methods such as the use of stimulating electrodes, the study of conscious patients and the analysis of epileptic seizures, that the brain alone can carry out the work that mind does. I conclude that it is easier to imagine the human being on the basis of two elements rather than a single one" ${ }^{21}$

Everything that goes on in the brain affects the immune system because there is a bi-directional circuit between the central nervous system and the immune system. Stress thoughts, acting on the hypothalamus through various neuromediator molecules, affect the immune system via HPA (hypothalamic-pituitary-adrenal) axis and the immune system affects the brain, via the same axis, through cytokines. 22,23

The biochemical composition, caused by stress, leads to immunodepression, a state that favors the onset of infectious, allergic, autoimmune and degenerative diseases. This fact was evidenced when Sheldon Cohen et al. published what was considered the first scientific evidence on the facilitation of illnesses by stress. ${ }^{24}$

But before that, psychologist Janice K. Kiecolt-Glaser of Ohio University had already shown in her research the decline in immune function due to stress and later observations confirmed the fact, and today it is common sense that stress harms the immune function. ${ }^{25-28}$

\section{MIND-SKIN COMMUNICATION}

That the skin receives interference from the mind is out of any discussion by self-evident phenomena. When someone goes through an embarrassing situation, there is a flushing of the faces; when someone gets angry, the skin turns red; when someone gets frightened, the skin becomes pale; when feeling terrified, the hair on the body erects. These reactions, which anyone can see, are so undeniable that there are expressions commonly used to represent them, such as being flushed with shame, anger red, scared white, cold sweat of fear, hair standing in terror.

This indicates that always, at all times, anyone has been able to prove that emotional states manifest in the skin. It is curious, therefore, that even today experts doubt that emotions experienced by people affect the skin all the time and, having the possibility to modify the color, temperature, humidity, sebaceous secretion, resistance, blood flow, i.e., their functional properties, they consequently have the power to produce imbalances translated in the form of dermatoses.

This doubt arose from the fact that, although physicians could witness the changes of the skin as effects of the emotions, the concepts implanted by the biomedical model demanded that the mechanism by which this was given was discovered and proven, without what, even if it were convincing at sight, it was not a scientific observation, and therefore its existence was unreliable. This concept is well illustrated by the Portuguese neurologist Antonio Damasio, a professor at the School of Medicine of the University of Iowa: "Western medicine has achieved glory through the expansion of internal medicine and surgical subspecialties, both of which are intended to diagnose and treat diseased organs and systems throughout the body. The brain was included because it was one of those organs. But its most precious product, the mind, has not been the subject of great concern on the part of the mainstream of Medicine ... The result has been an amputation of the concept of human nature with which Medicine works ... Medicine has been slow to realize that what people feel about their physical state is the main factor in the outcome of treatment". ${ }^{29}$

The missing link began to emerge with the first experience of the psychologist Robert Ader in 1970, and with the subsequent research in the same field, which formed what would constitute the new science Psychoneuroimmunology. These works have shown the path of mind-body communication, including the mind-skin relation. On this we published an article in 1992 in which we state that competence in dealing with emotions could be the decisive aspect for the emergence of many diseases and for the success of many treatments. ${ }^{30}$ Since then, countless researches have proven cutaneous effects of thoughts and emotions, such as delayed healing, inhi- 
bition of hair growth and reduction of barrier function. ${ }^{31-33}$

By the evolution of psychoneuroimmunological research, it is now known that mental activity causes electrical changes in the cerebral cortex, which are carried to the thalamus and hypothalamus. There, they are transduced into chemical substances, which are the messengers of thoughts, namely neurotransmitters, neurohormones and neuropeptides. These, by the circulation or by the nerves, reach all the cells of the organism and, logically, also the cells of the skin. In each cell, when picked up by the receptors, they are decoded so that the cells understand the message they represent. After decoding and understanding the message, the cells work according to the chemical order that originated in immaterial thoughts.

\section{PSYCHOSOMATIC NETWORK AND NICE SYSTEM}

Mind-body communication, as demonstrated by researches, occurs through messenger substances and cellular receptors. To these two elements, Dr. Candace Pert (1946-2013), who was chief of the Division of Brain Biochemistry of the National Institutes of Health of the United States, calls the molecules of emotion and names the psychosomatic network the set of neuropeptides and receptors distributed by the whole organism..$^{34,35}$

In this network, the emotions would be held. Dr. Pert said that emotions are produced in the moment the neuropeptides fit the cellular receptors: "These molecules are emotions, not their cause. What we experience as a feeling is the actual vibrational dance that happens when the peptides bind to their receptors, regardless of whether they occur in consciousness", and then they are physical and non-physical at the same time. ${ }^{36}$

The proximity of Langerhans cells and neurons in the presence of CGRP (calcitonin gene-related peptide), in addition to the expression of neurotrophic factors and receptors for neuropeptides in these cells, indicates the existence of a bidirectional communication in the skin between the immune system and the nervous system. Neuropeptides are present in nerve fibers and in all cutaneous cells, keratinocytes, immunocytes, fibroblasts, Langerhans cells and endothelial cells, constituting a neuro-immuno-cutaneous-endocrine system (NICE system). ${ }^{37-39}$

\section{THE ACTION OF STRESS}

The mind produces thoughts of two kinds: facilitators and limiting. According to the type of thought produced, it will inevitably give a pleasant, neutral or unpleasant sensation. The chain of events, as long as a thought is produced, is automatic because, in thinking, we produce chemicals in the brain. As the Indian endocrinologist Dr. Deepak Chopra explains, a thought is a boost of energy and information, as everything in nature. Beliefs, thoughts and emotions create the chemical reactions that sustain life in every cell. ${ }^{40}$

Stressful thoughts are of the most varied types, because they depend basically on the interpretation that each person gives to what goes in his/her mind. Any thought can be stressful to some, hilarious to others, neutral to others. Among the people who participate in the experience of riding a roller coaster, some enjoy themselves, others are frightened, others are terrified, others feel it as a bland activity. Some leave willing to return, others never want to go through the same situation again, and for others it is indifferent.
What makes sensations vary is how individuals perceive the experience. Some feel good, because, faced with the opportunity, their thoughts were of joy and this biochemical composition generated enthusiasm and euphoria; others created thoughts of fear and danger, and the resulting biochemical state were tension and dread.

The facts are neutral; the way each one considers them is what gives them the individual color and that changes them instantly. The sight of a vine curled up on the floor of a forest creates an immediate stress reaction on a hiker as a snake ready to attack; in the next instant, upon realizing its true and harmless nature, the state of stress ceases and calm is established. In an instant, the response of the organism changed from fight-or-flight to relaxation reaction at the same moment that the thought passed from threatening fantasy to harmless reality.

Each thought triggers the brain and it reacts according to the nature of the influx received. The brain does not interpret what the human being tells it through thoughtful words and images. Therefore, fantasy and reality produce the same biochemical states and emotions in the body. Consider the worries. When one cares about something that may happen at some future time, one actually experiences emotionally, by anticipation, what will supposedly occur. If it is an event that will cause displeasure or unhappiness, the individual will feel in the present the stress these feelings will bring. If the situation does not occur, the person will have already been stressed because, to the brain, that was real. In the same way, when someone thinks about what is going to happen in the next vacation, he/she produces the sensations he/she will probably have as if the person were there at that moment The individual will feel happy in advance.

What happens in the whole body through this process is on the skin. However, the skin is a special organ because of its visibility. When someone has a disorder in some internal organ, he/she feels bad and grieve, but it is an individual experience. When the disorder is in the skin, in addition to the unpleasant sensation of the cutaneous alteration, there is the disturbance by the appearance, by what others think, by the questions that are asked of it, and by the withdrawal or repulsion of the others. Physical sensations add a psychological state. ${ }^{41}$

Thoughts, therefore, affect the skin by the chemical mediators brought to the skin cells. Stress thoughts cause fight-or-flight reaction in the skin, which is carried out by means of substances such as $\mathrm{CRH}, \mathrm{ACTH}$, cortisol, catecholamines, prolactin, substance $\mathrm{P}, \mathrm{NGF}$ and others, starting a series of physiological and behavioral changes with the objective of adapting the organism to the pressure of the stress, which causes inflammation, pruritus and aging. ${ }^{42,43}$

\section{PSYCHODERMATOLOGY AND PSYCHODERMATOSES}

As research shows more and more, the skin is intensely affected by everything that goes on in the mind and, retrogradely, triggers thoughts and emotions. There is a permanent mind - nervous system - skin connection and a reciprocal relation between these three areas. The skin sends messages to the nervous system and the mind and this influences the skin. ${ }^{44,45}$

From this interaction, the field of Psychodermatology was developed, which can be defined as the concept that encompass- 
es all the personal and social consequences of dermatoses and the mental and emotional mechanisms involved in their origin, maintenance or aggravation.

Psychodermatoses are the skin changes that:

1. are caused by psychiatric problems;

2. cause psychiatric or psychological disorders due to its clinical manifestation;

3 . influence the psychological state and is maintained or aggravated by it.

In the first group are dermatoses triggered by pathological mental states, which can be accompanied by hallucinations, delusions, obsessions, compulsions, fixation in sick states, exaggeration of symptoms, severe depression and anxiety, which are diagnosed as schizophrenia, obsessive-compulsive disorder, hypochondria, major depressive disorder, generalized anxiety disorder, social phobia, bipolar disorder, personality disorder, posttraumatic stress disorder, body dysmorphic disorder.

The dermatoses of this group are preceded by the disturbed mental states and result from them. They are divided into four types: ${ }^{46}$

- Self-inflicted dermatoses - artificial dermatitis

epidermotilomania

excoriated acne

artificial cheilitis

onicophagy

malingering

Gardner-Diamond syndrome

- Dermatoses due to illusions and hallucinations - illusions of parasitoses

olfactory, tactile and corporal hallucination

hypochondriac illusions

bodily dysmorphic disorder

- Somatoform disorders - pruritus

allergies

glossodynia

vulvodynia

tricodynia

paresthesias

burning

erythrophobia

- Dermatoses by compulsion - hand eczema by repeated washing lichen simplex chronicus

trichotillomania

psychogenic excoriations

cutaneous hypochondriasis

body dysmorphic disorder

The manifestations of this group are the mirror of what goes on in the patient's mind. It is not possible to effectively care for patients without acting on mental disorders.

In the dermatoses of the second group, the mind is affected secondarily by the presence of skin changes. They are stigmatizing, unsightly, diseases, or that causes intense or prolonged symptoms such as stress, irritability, fear, shame, catastrophic prediction, anx- iety, depression, anger, self-rejection, isolation, despondency, and moral fatigue. In this group, psoriasis, vitiligo, atopic dermatitis, alopecia areata and hidradenitis are the most common; other dermatoses, with less intense effects, are acne, dyshidrosis, hyperhidrosis of the hands, feet and armpits, leprosy, herpes simplex, hypertrichosis, lichen planus, perioral dermatitis, rosacea, seborrheic dermatitis, scleroderma, lupus erythematosus, pemphigus, leg ulcers; dermatoses with a devastating effect on the psyche are ichthyoses, epidermolysis, hemangiomas and any other dermatosis interpreted as disastrous or harmful by the patient. In fact, any dermatoses can cause psychological imbalance and lead to emotional tension, depending on the mental representation of the patient.

In the third group, both the dermatoses affect the psyche as it affects the clinical picture, causing its aggravation or its maintenance and resistance to the treatment or facilitating the cure. Many are part of the second group to which are added allergies, nummular dermatitis, infectious dermatitis and serious diseases such as neoplasias because, as already mentioned, stress, worries, discouragement, negative vision and everything that depletes organic energies compromise the immune system and impedes recovery of health.

\section{INTERDISCIPLINARY CARE}

Facing permanent mind-skin interaction it is necessary that the patient is treated as a unit consisting of several vibratory levels, which correspond to cutaneous, emotional and mental aspects. It is necessary to deal with clinical conditions using the resources available to Dermatology, but also with those that are in the domain of the other areas participating in these diseases, namely Psychiatry and Psychology.

First, it is necessary to be clear that it is convenient for the dermatologist to acquire certain skills that go beyond diagnosis and management of skin alterations. The specialist who understands that the patient's emotional complaints are part of the clinical picture and has the capacity to explore them and provide some kind of support to them can be more effective in his/her treatment.

In many cases, dermatoses are followed by aspects of inability to control emotions that require a systematic and specialized correction for which the dermatologist would not have preparation or time. The dermatologist can obtain basic preparation to attend to and explore the patient's emotional states, giving him/her, through adequate language and conscientious questions, conditions to see the real dimension of the problem and to envision new options. Often, a welcoming attitude of the doctor facilitates the solution by the patient. However, a more thorough and systematic work requires the participation of a psychologist, preferably someone interested in dermatological issues.

And in the psychodermatoses of the first group, many of which involve frank psychopathology, the participation of a psychiatrist is essential for the accurate diagnosis of the underlying disorder and follow-up with specific medications, which require indepth knowledge and daily experience in controlling their actions and possible undesirable adverse events. Despite this, it is necessary that the dermatologist has basic knowledge of Psychopharmacology and minimal condition of handling psychoactive drugs to attend to simpler cases. ${ }^{47}$ 


\section{INTEGRATED THERAPEUTIC RESOURCES}

Considering this participation of emotions and mind in a great number of cutaneous diseases, it is necessary to integrate all the resources that can attend to these three areas.

Basically, the dermatologist will give attention to the state of the skin, seeking to correct the changes according to the best dermatological and surgical techniques.

Remembering that chronic stress always harms any organic state, it is important to master mind-body anti-stress techniques. They are natural attitudes which, surprisingly, are not taught and therefore are not followed by patients or doctors and can keep stress at a non-harmful level without costing money. These techniques can be applied during the consultation, and the physician should instruct patients to practice them routinely to maintain their physical and mental balance. The fundamental ones are four: upright posture, change of breathing pattern, muscle relaxation and meditation. All have proven effectiveness in reducing stress and in favoring the body's balance. The simple conscious breathing, with change of the thoracic pattern to the abdominal one, produces important modifications in the organism in the sense of the physiological and psychological balance. ${ }^{48}$ The cardiologist Herbert Benson began the application of stress reduction techniques in the 1960s at Massachusetts General Hospital and developed a Relaxation and Resilience Response Program consisting of meditation, relaxation, social support, cognitive skills training, and positive psychology. Its application has indicated that mind-body interventions reduce the individual burden of disease and decrease the need for people to resort to health services. ${ }^{49}$ In recent years, it has been studied closely, in the light of results obtained over many years by Dr. Jon Kabat-Zinn, Emeritus Professor of Medicine at the University of Massachusetts Medical School, a type of meditation called mindfulness meditation. ${ }^{50-54}$

Intervention with psychoactive drugs in cases of marked mental changes such as personality disorder, bipolar disorder, narcissistic personality disorder, depressive disorders, anxiety disorders, posttraumatic stress disorder, schizophrenia, obsessive-compulsive disorder, should be conducted by psychiatrist in consultation with Dermatology because it involves another area of Medicine..$^{55}$

As we have already focused on, almost all skin diseases are capable, to a greater or lesser degree, of emotionally affecting patients. There is today the concept that in certain diseases, however small it may be, to refer the patient to a psychologist, as if the mind were the exclusive cause of the disease, which, once attended to, will lead to a cure. This aspect deserves thoughtful consideration by the specialist because often the patient deals perfectly well with the acne without it affecting him/her emotionally. But for some individuals, , the degree of emotional impairment is so complex that it becomes imperative to refer the patient to psychotherapy. There are several types of psychotherapy and each person adapts to some. The most commonly used is cognitive-behavioral therapy, which is acknowledged to be effective in many cases. ${ }^{56}$ Other techniques include transactional analysis, bioenergetic analysis, gestalt therapy, psychodrama, and reprogramming techniques such as neurolinguistic programming, timeline therapy, EMDR (Eye Movement De- sensitization and Reprocessing), and energy techniques such as TFT (Thought Field Therapy) and EFT (Emotional Freedom Techniques). Although the mode of action of some of them is not perfectly clear, it is necessary to maintain the integrative concept. Nothing should be disregarded, because each person is unique and experiences disease on his/her own way. There are reports of positive effects with all these techniques in individual cases or in large numbers of people.

Other resources, well known and employed, are biofeedback, guided imagery, visualization and support groups ${ }^{57-58} \mathrm{Hyp}-$ nosis is a technique with proven effects on the brain and capable of producing unexpected results, besides being usable in a large number of dermatoses. ${ }^{59}$ It could be put into practice by a greater number of doctors because of its vast reach. There is also self-hypnosis and self-massage, which are self-applying techniques, as well as yoga and tai chi chuan, originating in India and China, the former being a philosophy of life, which integrates mind and body, and the second, originated from Martial arts, producing effects on the body's energizing.

It is important to remember that, rarely, dermatologists work with the skin's ability to influence the nervous system and the immune system by touch. Perhaps this is a consequence of the dermatologist being trained almost exclusively on diseased skin and not having attention focused first on normal skin and its meaning and potentiality. Skin touch and skin stimulation in the form of massage have the power to facilitate recovery from burns, reduce levels of stress hormones and of anxiety, increase delta waves, indicative of relaxation, and decrease alpha and beta waves in the electroencephalogram, decrease the salivary cortisol and raise the cytotoxic capacity by increasing the number of NK cells..$^{60-62}$ This resource is available to specialists and can be of great value in the treatment of psychodermatoses, using the assistance of massage therapists.

\section{FINAL CONSIDERATIONS}

Because it involves the skin, the nervous system and the mind, Psychodermatology needs the collaboration and integration of the dermatologist, the psychiatrist and the psychologist without which the psychodermatoses will not be treated in their complexity and will not be focused on their origin. More than an aesthetic impairment, they are associated with a diversity of psychopathological problems, which affect the patient's family and social life. Dermatologists should become familiar with basic psychopharmacology and simple non-pharmacological interventions. They also need to have good access to the patient, which depends on considering the situation from the perspective of those who experience the disease. In treatment, they should include pharmacological and non-pharmacological resources and always use stress reduction techniques, the major causative agent of diseases. It is convenient, given the current level of knowledge about the mind-skin connection, that Dermatology services have psychiatrists and psychologists for interconsultation acting jointly with dermatologists. The absence of this care to patients reduces the dermatological consultations to attempts to repair the effects without seeking the causes, making patients captive attendants of the services without offering a perspective of solution. $\square$ 


\section{REFERENCES}

1. Ader R, Cohen N. Behaviorally conditioned immunosupression. Psychosom Med. 1975;37:333-40

2. Pan W, Zhou H. Integrative Medicine: A Paradigm Shift in Clinical Practice. Int J Integr Med 2013;21:1-6.

3. Ludwig MWB, Müller MC, Redivo LB, Calvetti PU, Silva LM, Hauber LS. Facchin THJ. Psicodermatologia e as intervenções do psicólogo da Saúde. Mudanças Psicol Saúde. 2008;16:37-42.

4. Basavaraj KH, Navya MA, Rashmi R. Relevance of psychiatry in dermatology; present concepts. Indian J Psychiatry. 2010;52:270-5.

5. Mercan S, Kivanç Altunay I. Psychodermatology: a collaborative subject of psychiatry and dermatology. Turk Psikiyatri Derg. 2006;17:305-13.

6. Paus R, Theoharides TC, Arck PC. Neuroimmunoendocrine circuitry of the "brainskin' connections. Trends Immunol. 2006;27:32-9.

7. Montagu A. Tocar - 0 Significado Humano da Pele. São Paulo: Summus Editorial; 1988.

8. Hatfield RW. Touch and Human Sexuality. In Bullough VL, Bullough B. Stein editors. Human Sexuality: An Encyclopedia. New York: Garland Publishing; 1994.

9. Patterson $\mathrm{CH}$, Hidore SC. The Primary Prevention of Psychosocial Disorders: A Person/ Client Centered Perspective. PCJ. 1997;4:8-17.

10. Field TM, Schanberg SM, Scafidi F, Bauer CR, Vega-Lahr N, Garcia R, et al. Tactile/ kinesthetic stimulation effects on preterm neonates. Pediatrics. 1986;77:654-8.

11. Picardi A, Abeni D, Renzi C, Braga M, Puddu P, Pasquini P. Increased Psychiatric Morbidity in Female Outpatients with Skin Lesion on Visible Parts of the Body. Acta Derm Venereol. 2001;81:410-4.

12. Gupta MA. Psychosocial aspects of common skin diseases. Can Fam Physician 2002 Apr;48:660-2, 668-70.

13. Saleh HM, Salem SAM, El-Sheshetawy RS, El-Samei AMA. Comparative Study of Psychiatric Morbidity and Quality of Life in Psoriasis, Vitiligo and Alopecia Areata. EDOJ 2008;4:1-28.

14. Koo J, Lebwohl A. Psychodermatology: The Mind and Skin Connection. Am Fam Physician. 2001;64:1873-8.

15. Dalgard FJ, Gieler U, Tomas-Aragones L, Lien L, Poot F, Jemec GB et al. The Psychological Burden of Skin Diseases: A Cross-Sectional Multicenter Study among Dermatological Out-Patients in 13 European Countries. J Invest Dermatol. 2015;135:984-91.

16. McEwen BS. Brain on stress: How the social environment gets under the skin Proc Natl Acad Sci U S A. 2012;109:17180-5.

17. Selye H. A Syndrome Produced by Diverse Nocuous Agents. Nature. 1936;138:32.

18. Hanson R, Mendius R. 0 Cérebro de Buda. São Paulo: Alaude Editorial; 2012.

19. Chopra D, Mlodinov L. Ciência x Espiritualidade. Rio de Janeiro: Sextante; 2012. p. 194.

20. Del Nero HS. 0 Sítio da Mente. São Paulo: Collegium Cognitio; 1997. p. 447.

21. Custance AC. The Mysterious Matter of Mind. 2nd ed. Ancaster, Can.: Doorway Publication; 2001

22. Bilbo SD, Schwarz JM. The Immune System and Developmental Programming of Brain and Behavior. Front Neuroendocrinol. 2012;33:267-86.

23. Dantzer R, O'Connor JC, Freund GG, Johnson RW, Kelley KW. From inflammation to sickness and depression: when the immune system subjugates the brain. Nat Rev Neurosci. 2008:9:46-56

24. Cohen S, Tyrrell DA, Smith AP. Psychological stress and susceptibility to the common cold. N Engl J Med. 1991 Aug 29;325(9):606-12.

25. Kiecolt-Glaser JK, Garner W, Speicher C, Penn GM, Holliday J, Glaser R Psychosocial modifiers of immunocompetence in medical students. Psychosom Med. 1984;46:7-14

26. Segerstrom SC, Miller GE. Psychosocial Stress and the Human Immune System: A Meta-Analytic Study of 30 Years of Inquiry. Psychol Bull. 2004;130:601-30.

27. Glaser R, Kiecolt-Glaser J. Stress Damages Immune System and Health. Discov Med. 2005:5:165-9.

28. Hussain D. Stress, Immunity, and Health: Research Findings and Implications. Int J Psychosocial Rehabilitation. 2010;15:94-100.

29. Damásio A. O Erro de Descartes. São Paulo: Companhia das Letras; 1996. p. 287.

30. Azambuja R. A conexão psiconeuroimunológica em dermatologia. An Bras Dermatol. 1992. 67:3-6

31. Marucha PT, Kiecolt-Glaser JK, Favagehi M. Mucosal wound healing is impaired by examination stress. Psychosom Med. 1998;60:362-5.

32. Botchkarev VA. Stress and the Hair Follicle - exploring the connections. Am J
Pathol. 2003;162:709-12.

33. Garg A, Chren MM, Sands LP, Matsui MS, Marenus KD, Feingold KR, et al. Psychological Stress Perturbs Epidermal Permeability Barrier Homeostasis. Arch Dermatol. 2001;137:53-9.

34. Pert CB. Molecules of Emotion - the science behind mind-body medicine. New York: Touchstone; 1999.

35. Pert CB, Ruff MR, Weber RJ, Herkenham M. Neuropeptides and their receptors: a psychosomatic network. J Immunol. 1985;135:820s-826s.

36. Pert CB. Conexão Mente-Corpo-Espírito. São Paulo: Pro Libera Editora; 2009. p. 39

37. O'Sullivan RL, Lipper G, Lerner EA. The neuro-immuno-cutaneous-endocrine network: relationship of mind and skin. Arch Dermatol. 1998;134:1431-5.

38. Hall JM, Cruser D, Podawiltz A, Mummert DI, Jones H, Mummert ME. Psychological stress and the cutaneous immune response: Roles of the HPA axis and the sympathetic nervous system in atopic dermatitis and psoriasis. Dermatol Res Pract. 2012;2012:403908.

39. Slominski AT, Zmijewski MA, Zbytek B, Tobin DJ, Theoharides TC, Rivier J. Key role of CRF in the skin stress response system. Endocr Rev. 2013;34:827-84.

40. Chopra D. Ageless Body, Timeless Mind. New York: Harmony Books; 1993. p. 6; 21.

41. van Laarhoven Al, Walker AL, Wilder-Smith $\mathrm{OH}$, Kroeze $\mathrm{S}$, van Riel PL, van de Kerkhof PC, et al. Role of induced negative and positive emotions in sensitivity to itch and pain in women. Br J Dermatol. 2012;167:262-9.

42. Arck PC, Slominski A, Theoharides TC, Peters EM, Paus R. Neuroimmunology of Stress: Skin Takes Center Stage. J Invest Dermatol. 2006;126:1697-704.

43. Chen Y, Lyga J. Brain-skin connection: stress, inflammation and Skin Aging. Inflamm Allergy Drug Targets. 2014;13:177-90

44. Hoffmann FS, Zogbi H, Fleck P, Müller MC. A integração mente e corpo em psicodermatologia. Rev Psicol. 2005;7:51-60.

45. Silva MN, Silva RN, Soares GMT. Influência das dermatoses no psiquismo de pacientes dermatológicos. Med Cut lber Lat Am. 2011;39:209-210.

46. Harth W, Gieler U, Kusnir D, Tausk FA. Clinical Management in Psychodermatology. Berlin, Heidelberg: Springer Verlag; 2009.

47. Escalas J, Guerra A, Rodríguez-Cerdeira MC. Tratamiento con psicofármacos de Ios trastornos psicodermatológicos. Actas Dermatosifiliogr. 2010;101:485-94.

48. Ramirez JM. The integrative role of the sigh in psychology, physiology, pathology, and neurobiology.. Prog Brain Res. 2014;209:91-129.

49. Stahl JE, Dossett ML, LaJoie AS, Denninger JW, Mehta DH, Goldman R, et al. Relaxation Response and Resiliency Training and Its Effect on Healthcare Resource Utilization. PLoS One. 2015;10:e0140212.

50. Kabat-Zinn J, Wheeler E, Light T, Skillings A, Scharf MJ, Cropley TG, et al. Influence of a Mindfulness Meditation-Based Stress Reduction Intervention on Rates of Skin Clearing in Patients With Moderate to Severe Psoriasis Undergoing Phototherapy (UVB) and Photochemotherapy (PUVA). Psychosom Med. 1998;60:625-32.

51. Kabat-Zinn J. Mindfulness-Based Interventions in Context: Past, Present, and Future. Clin Psychol Sci Prac. 2003;10:144-56.

52. Davidson RJ, Kabat-Zinn J, Schumacher J, Rosenkranz M, Muller D, Santorelli SF, et al. Alterations in Brain and Immune Function Produced by Mindfulness Meditation. Psychosom Med. 2003;65:564-70.

53. Grossman P, Niemann L, Schmidt S, Walach H. Mindfulness-based stess reduction and health benefits. J Psychosom Res. 2004;57:35-43.

54. Carmody J, Baer RA. Relationships between mindfulness practice and levels of mindfulness, medical and psychological symptoms and well-being in a mindfulness-based stress reduction program. J Behav Med. 2008;31:23-33.

55. Gupta MA, Gupta AK, Ellis CN, Koblenzer CS. Psychiatric Evaluation of the Dermatology Patient. Dermatol Clin. 2005;23:591-9.

56. Lavda AC, Webb TL, Thompson AR. A meta-analysis of the effectiveness of psychological interventions for adults with skin conditions. $\mathrm{Br} \mathrm{J}$ Dermatol. 2012;167:970-9

57. Shenefelt PD. Psychological interventions in the management of common skin diseases. Psychol Res Behav Manag. 2010:3:51-63.

58. Fried RG. Nonpharmacological Management of Psychodermatologic Conditions. Semin Cutan Med Surg. 2013 Jun;32(2):119-25

59. Shenefelt PD. Hypnosis in dermatology. Arch Dermatol. 2000;136:393-9.

60. Field T, Peck M, Krugman S, Tuchel T, Schanberg S, Kuhn C, et al. Burn injuries benefit from massage therapy. J Burn Care Rehabil. 1998;19:241-4. 
61. Field T, Ironson G, Scafidi F, Nawrocki T, Goncalves A, Burman I, et al. Massage therapy reduces anxiety and enhances EEG pattern of alertness and math computations. Int J Neurosci. 1996;86:197-205.

62. Ironson G, Field T, Scafidi F, Hashimoto M, Kumar M, Kumar A et al. Massage Therapy is Associated with Enhancement of the Immune System's Cytotoxic Capacity. Int J Neurosci. 1996;84:205-17.
MAILING ADDRESS:

Roberto Doglia Azambuja

SQS 316 - Bloco G - Apto. 301

70387-070 - Brasília - DF

Brazil

Email: robertodoglia@gmail.com

How to cite this article: Azambuja RD. The need of dermatologists, psychiatrists and psychologists joint care in psychodermatology. An Bras Dermatol. 2017;92(1):63-71. 